\title{
Potential Ameliorative Effects of Qing Ye Dan Against Cadmium Induced Prostatic Deficits via Regulating Nrf-2/HO-1 and TGF- $\beta 1 /$ Smad Pathways
}

\author{
Lifen Du $\quad$ Yongfang Lei ${ }^{b} \quad$ Jinglou Chen ${ }^{a} \quad$ Hongping Song ${ }^{a} \quad$ Xinying Wu ${ }^{a}$ \\ aDepartment of Pharmacy, Puai Hospital, Tongji Medical College, Huazhong University of Science and \\ Technology, Wuhan, 'bepartment of Pharmacy, Tongji Hospital, Tongji Medical College, Huazhong \\ University of Science and Technology, Wuhan, China
}

\section{Key Words}

Cadmium • Prostate • Qing Ye Dan • Transforming growth factor- $\beta 1$ - Nuclear related factor-2

\begin{abstract}
Background/Aims: Cadmium (Cd) is an environmental pollutant with reproductive toxicity. Swertia mileensis is used in Chinese medicine for the treatment of prostatic deficits and named as Qing Ye Dan (QYD). This study was undertaken to investigate the potential protective effects of QYD against Cd-induced prostatic deficits. Method: Rat model of prostatic deficits was induced by $0.2 \mathrm{mg} / \mathrm{kg} / \mathrm{d} \mathrm{CdCl}_{2}$ subcutaneous injection for 15 days. The prostatic oxidative stress was evaluated by detecting the levels of malondialdehyde, nitric oxide, reduced/ oxidized glutathione, total sulfhydryl groups and enzymatic antioxidant status. The prostatic inflammation was estimated by testing the levels of pro-inflammatory cytokines. The levels of epithelial-mesenchymal transition (EMT) markers E-cadherin, fibronectin, vimentin and $\alpha$-smooth muscle actin were measured by qPCR analysis. Additionally, the prostatic expressions of transforming growth factor- $\beta 1$ (TGF- $\beta 1$ ), type I TGF- $\beta$ receptor (TGF- $\beta R I$ ), Smad2, phosphorylation-Smad2 ( $\mathrm{p}-\mathrm{Smad} 2$ ), Smad3, $\mathrm{p}-\mathrm{Smad} 3, \mathrm{Smad} 7$, nuclear related factor-2 (Nrf2), heme oxygenase-1 (HO-1), B-cell CLL/lymphoma (BCl)-2 and Bcl-2-associated $\mathrm{X}$ protein (Bax) were measured by western blot assay. Results: It was found that QYD ameliorated the $\mathrm{Cd}$-induced prostatic oxidative stress and inflammation, attenuated prostatic EMT, inhibited the TGF- $\beta 1 /$ Smad pathway, increased Bcl-2/Bax ratio and enhanced the activity of Nrf-2/HO-1 pathway. Conclusion: These results showed that QYD could ameliorate $\mathrm{Cd}$-induced prostatic deficits via modulating Nrf-2/HO- 1 and TGF- $\beta 1 / \mathrm{Smad}$ pathways.
\end{abstract}

Jinglou Chen, and Hongping Song

\section{KARGER}




\section{Introduction}

The problems of environmental pollution (such as heavy metal and pesticide residues) seriously affect human health. Cadmium (Cd) is a widely existed heavy metal which commonly used in the modern industrial production. Because the contamination of $\mathrm{Cd}$ in soil and water, people are exposed to Cd via the bioaccumulation from the food chain [1, 2]. Furthermore, human are exposed to $\mathrm{Cd}$ through active and passive smoking since that $\mathrm{Cd}$ is also present in tobacco [3]. Cd is a non-biodegradable and non-essential heavy metal for human beings. The biologic half-life of $\mathrm{Cd}$ is more than 30 years $[4,5]$. Study indicates that the accumulation of Cd causes damages on reproductive system [6]. Cd has the functions of disrupting endocrine, as well as interfering with the morphogenesis and susceptibility to diseases of reproductive organs $[1,7]$. When compared to other heavy metals, Cd can stimulate the emergence of organ disorders at a relatively lower dose [3]. Especially for prostate, Cd requires much less time than other toxicant to produce the malignantly transformation on normal prostate epithelial cells [8]. Moreover, Cd triggers the prostatic local inflammatory responses and fibrillar rearrangement, damages the prostatic balance of collagen deposition and degradation, and disturbs the homeostasis of proliferation and apoptosis $[7,9,10]$. Increased collagen deposition and prostatic fibrosis are critical factors for the development of lower urinary symptoms (LUTS) and urinary obstructive symptoms [11].

Swertia mileensis is a member of Swertia genus and traditionally used in Chinese folk medicine named as "Qing Ye Dan" (QYD). Previous study indicated that QYD could ameliorate testosterone-induced prostatic hyperplasia and epithelial-mesenchymal transition (EMT) [12]. However, the potential protective effects of QYD on Cd-induced prostatic deficits still remained unclear. So, this study was undertaken to investigate the effects of QYD on Cdinduced prostatic deficits in rats and to explore the possible mechanisms.

\section{Materials and Methods}

\section{HPLC-MS/MS analysis for QYD}

The extract of QYD was prepared according to our previous report [12]. Standard swertiamarin (purity $98.3 \%$ ) and rutin ( IS, purity $\geqslant 90.5 \%$ ) were purchased from the National Institute for Food and Drug Control (Beijing, China). Gentiopicroside (purity $\geqslant 98 \%$ ) and sweroside (purity $\geqslant 98 \%$ ) were purchased from Yuanye Biological Technology Co., Ltd. (Shanghai, China). Manglferin (purity $\geqslant 98 \%$ ) was got from Aladdin industrial Co., Ltd. (Shanghai, China). HPLC-grade acetonitrile was purchased from Fisher Scientific Inc. (Fair lawn, USA).

Shimadzu LC-20A series HPLC (Kyoto, Japan) was linked to the QTRAPI 5500 (AB SCIEX, Framingham, MA, USA). A $3 \mu$ of sample was injected into a Leapsil C18 column $(150 \times 2.1 \mathrm{~mm}, 2.7 \mu \mathrm{m})$ (Dikma Technology, China) and held at $40{ }^{\circ} \mathrm{C}$. The mobile phase consisted of solvent A ( $0.4 \%$ formic acid in water) and solvent $\mathrm{B}$ (acetonitrile) with a constant flow rate of $0.3 \mathrm{ml} / \mathrm{min}$. The binary gradient was as follows: $12 \%-20 \% \mathrm{~B}$ (0-8 min), 20\%-95\% B (8-8.1 min), 95\% B (8.1-9.8min), 95\%-12\% B (9.8-9.9 min) and equilibrated for a further $3.6 \mathrm{~min}$ until the injection of the next sample. The column effluent was introduced into the Mass Spectrometer equipped with an electrospray ionization (ESI) source. The mass spectrometer was operated in positive ion mode. The ion spay voltage was set at $4500 \mathrm{~V}$, the nebulizer gas 40 psi, the auxiliary gas 40 psi, the curtain gas at 25 psi and the collision gas at medium.

\section{Animals and administration}

The male Wistar rats $(180 \pm 20 \mathrm{~g})$ were supplied by the Centers of Disease Control and Prevention of Hubei Province, China. The animals were housed at a controlled room (temperature $22 \pm 3{ }^{\circ} \mathrm{C}$, humidity 50 $\pm 10 \%$ and $12 \mathrm{~h}$ light: $12 \mathrm{~h}$ dark cycle) and fed with standard diet and water ad libitum. After acclimatization to the laboratory, the rats were weighted and randomly divided into four groups $(n=8)$ : the vehicle control group (control), the Cd model group (Cd), the QYD treated control group (QYD) and Cd + QYD treated group $(C d+Q Y D)$. The rats from Cd and Cd + QYD groups were subcutaneously injected with $0.2 \mathrm{mg} / \mathrm{kg} / \mathrm{d} \mathrm{CdCl}_{2}$ for 15 days [13]. The Cd + QYD and QYD groups were daily orally treated with $200 \mathrm{mg} / \mathrm{kg}$ QYD for 15 days. 


\section{Cellular Physiology Cell Physiol Biochem 2017;43:1359-1368 \begin{tabular}{l|l|l} 
and Biochemistry & Dublished onlIne: October 09, 2017 & $\begin{array}{l}\text { C } 2017 \text { The Author(s). Published by S. Karger AG, Basel } \\
\text { www.karger.com/cpb }\end{array}$
\end{tabular}}

Du et al.: Qing Ye Dan Protects Against Prostatic Deficits

At the end of the experimental period, the body weight was recorded. The prostatic lateral lobes samples were collected, weighted and excised. One part tissue was stored at $-80{ }^{\circ} \mathrm{C}$ for the following western blot assay and quantitative RT-PCR (qPCR) analysis. The rest tissue was made into the tissue homogenate using 10 volumes of ice cold $0.9 \% \mathrm{NaCl}$ solution and stored at $-80^{\circ} \mathrm{C}$ for the evaluation of prostatic oxidative stress and inflammation. All the animal experiments were performed in accordance with the ethical rules in the NIH Guidelines for the Care and Use of Laboratory Animal and approved by the Institutional Animal Care and Use Committee at Puai Hospital, Tongji Medical College, Huazhong University of Science and Technology.

\section{Evaluation for the prostatic oxidative stress and inflammation}

The prostatic level of oxidative stress was evaluated by measuring the prostatic levels of malondialdehyde (MDA), glutathione (GSH), oxidized glutathione (GSSH), total sulfhydryl groups (T-SH), nitric oxide (NO) and the activities of antioxidant enzymes superoxide dismutase (SOD), catalase (CAT) and glutathione peroxidase (GPx) using commercial available kits (Nanjing Jiancheng Bioengineering Institute, China). The prostatic inflammation was estimated by assaying the prostatic levels of interleukin (IL)-1 $\beta$, IL-6 and tumor necrosis factor (TNF)- $\alpha$ using commercial available kits (Boster Biological Technology Co., Ltd. China). All the procedures were performed according to the manufacture's instructions.

\section{Western blot analysis}

The prostatic expressions of transforming growth factor- $\beta 1$ (TGF- $\beta 1$ ), type I TGF- $\beta$ receptor (TGF$\beta R I$ ), Smad2, phosphorylation-Smad2 (p-Smad2), Smad3, p-Smad3, Smad7, nuclear related factor-2 (Nrf2), heme oxygenase-1 (HO-1), B-cell CLL/lymphoma (Bcl)-2 and Bcl-2-associated X protein (Bax) were assessed by western blot analysis. Tissue protein samples were separated by $10 \%$ SDS-polyacrylamide gel electrophoresis and then transferred to a PVDF membrane by electrophoretic transfer. The membranes were blocked for $1 \mathrm{~h}$ at $37^{\circ} \mathrm{C}$ with $5 \%$ nonfat milk in Tris-buffered saline, and then incubated overnight at $4^{\circ} \mathrm{C}$ with the primary antibodies (anti-TGF- $\beta 1$, TGF- $\beta$ RI, Smad2, p-Smad2, Smad3, p-Smad3, Smad7, Bcl-2 and Bax (Abcam, UK), or -Nrf-2 and HO-1 (Proteintech Group, USA)), respectively. After washed with TBST, the membranes were incubated with horseradish peroxidase-conjugated secondary antibodies in TBST with $3 \%$ nonfat milk for $1 \mathrm{~h}$ at room temperature. Immunoblots were developed and then the quantification of bands was determined by integrated optical density analysis using Gel-Pro Analyzer software. The result of nuclear Nrf-2 was normalized using LaminB as an internal control. The other data were normalized using $\beta$-actin as an internal control.

\section{qPCR analysis for prostatic EMT markers}

The prostatic levels of EMT makers E-cadherin, vimentin, $\alpha$-SMA and fibronectin were estimated by qPCR according to our previous study [12]. The prostatic tissue samples were ground in liquid nitrogen and the total RNA was extracted from each sample using Trizol reagent. The isolated total RNA was quantified using gel electrophoresis. The qPCR was performed using a fast qPCR master mix kit (ABI, USA) in a realtime PCR system according to the manufacturer' protocol. Post-PCR melt curve analysis was used to control the PCR product specificity. Relative expressions levels were calculated using $2^{-\Delta \Delta C t}$ equation. The primer sequences of E-cadherin, vimentin, $\alpha$-SMA and fibronectin were showed in Table 1. GAPDH was used as the internal standard.

\section{Statistical analysis}

The values were presented as mean \pm S.D. Results were analyzed statistically by one-way ANOVA followed by Tukey's multiple comparison using SPSS 11.5. Differences were considered as significant at $p<0.05$.

Table 1. The primer sequences

\begin{tabular}{lcc}
\hline Gene & Forward primer & Reverse primer \\
\hline E-cadherin & 5'-TCACAGTCAAACGGCATCTAAA-3' & 5'-GGGCAGTTGATGGGAGGG-3' \\
Vimentin & 5'-TGCCAACCGGAACAACGAT-3' & 5'-AATTCTCTTCCATTTCACGCATC-3' \\
$\alpha$-SMA & 5'-CGGGCATCCACGAAACCA-3' & 5'-GAGCCGCCGATCCAGACA-3' \\
Fibronectin & 5'-CCCTACCAAGGCTGGATGAT-3' & 5'-GAGCAGGTTCCCTCTGTTGTC-3' \\
\hline
\end{tabular}




\section{Results}

Chromatographic analysis of QYD

The HPLC-MS/MS chromatogram of QYD is showed in Fig. 1. The content of swertiamarin, sweroside, gentiopicroside and manglferin in QYD was $11.37 \pm 1.26,1.26 \pm 0.19,1.42 \pm 0.25$, $3.16 \pm 0.38 \%$, respectively.

Effects of QYD on the levels of body weight, prostate weight, and food intake

As can be seen from Table $2, \mathrm{CdCl}_{2}$ injection causes a significant decrease in the rat body weight. Daily co-treated with $200 \mathrm{mg} / \mathrm{kg}$ QYD significantly enhanced the body weight when compared to the Cd model group. Treated with $200 \mathrm{mg} / \mathrm{kg} / \mathrm{d}$ QYD alone (without Cd injection) did not significantly $(p>0.05)$ affect the body weight, prostate weight and food intake when compared to the vehicle control.

\section{Effects of QYD on prostatic oxidative stress and inflammation}

Fig. 2 represents the effects of QYD on prostatic oxidative stress in rats injected with Cd. Cd contributed to much higher prostatic levels of GSSG, MDA and NO, lower levels of GSH and T-SH, as well as an obviously inhibited prostatic enzymatic antioxidant status when compared to the vehicle control. QYD significantly reduced the levels of GSSG, MDA and NO, as well as enhanced the concentrations of GSH and T-SH. QYD also attenuated the diminish

Fig. 1. The HPLC-MS/MS analysis for the characteristics compounds in QYD. A: swertiamarin; B: sweroside; C: gentiopicroside; D: mangiferin; E: IS rutin.

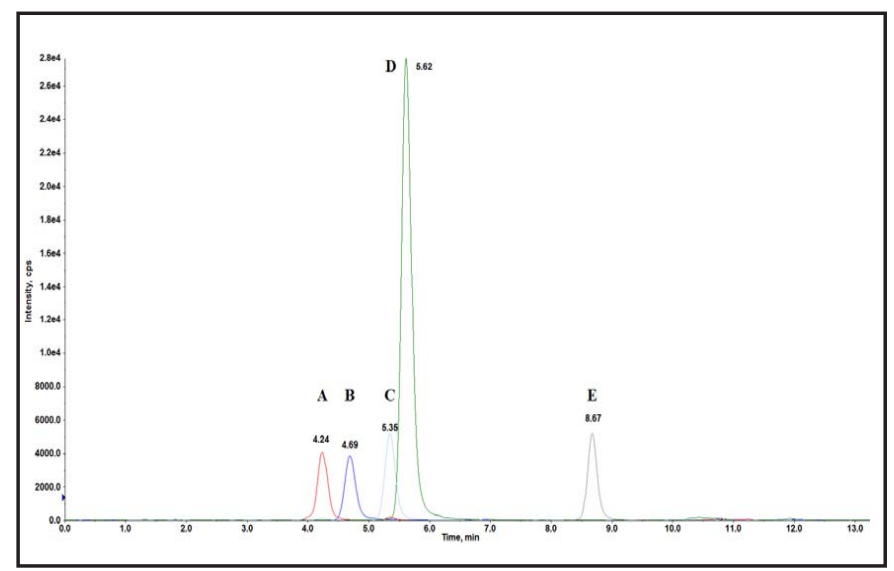

Table 2. Effects of QYD on body weight, prostate weight and food intake in rats injected with $\mathrm{Cd}$. ${ }^{* *} \mathrm{p}<0.01$ compared to the vehicle control, ${ }^{\# \#} \mathrm{p}<0.01$ compared to the $\mathrm{Cd}$ model

\begin{tabular}{lcccccc}
\hline \multirow{2}{*}{ Group } & Initial body & Final body & Prostate & Prostate & $\begin{array}{c}\text { Initial food } \\
\text { intake }(\mathrm{g} / 100\end{array}$ & Final food \\
& weight $(\mathrm{g})$ & weight $(\mathrm{g})$ & weight $(\mathrm{g})$ & index $(\%)$ & $\mathrm{g} / \mathrm{d})$ & $(\mathrm{g} / 100 \mathrm{~g} / \mathrm{d})$ \\
\hline Vehicle & $222.50 \pm 14.54$ & $319.62 \pm 22.73^{\# \#}$ & $1.55 \pm 0.26$ & $0.483 \pm 0.046$ & $14.14 \pm 1.61$ & $10.16 \pm 0.94$ \\
Cd & $224.38 \pm 14.90$ & $276.25 \pm 16.94^{* *}$ & $1.35 \pm 0.26$ & $0.486 \pm 0.068$ & $13.56 \pm 1.22$ & $8.56 \pm 0.57$ \\
QYD & $218.75 \pm 11.44$ & $313.75 \pm 22.57^{\# \#}$ & $1.58 \pm 0.25$ & $0.502 \pm 0.042$ & $13.93 \pm 1.63$ & $10.66 \pm 1.04$ \\
Cd+QYD & $224.62 \pm 17.36$ & $299.50 \pm 17.16^{* * \# \#}$ & $1.48 \pm 0.20$ & $0.493 \pm 0.40$ & $13.44 \pm 1.58$ & $9.69 \pm 0.88$ \\
\hline
\end{tabular}




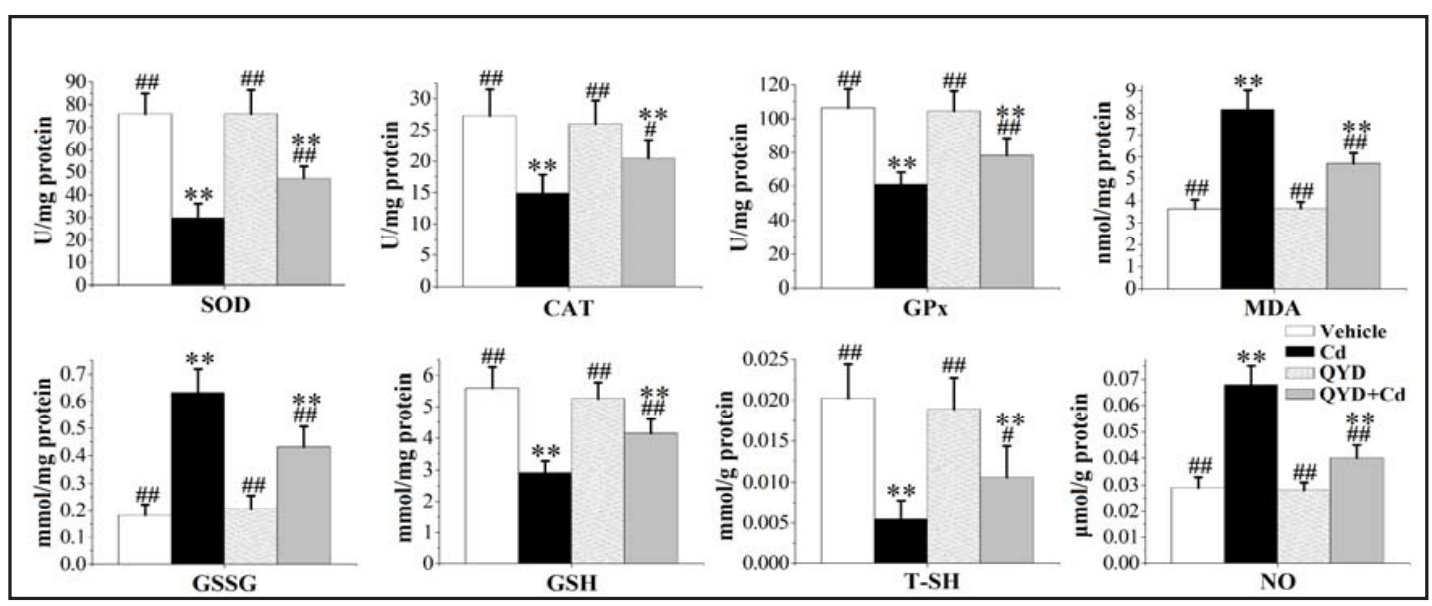

Fig. 2. Evaluation for the prostatic oxidative stress. Effects of QYD on the prostatic activities of SOD, CAT and GPx as well as the levels of MDA, GSSH, GSH, NO and T-SH in rats injected with Cd. ${ }^{* *} \mathrm{p}<0.01$ compared to the vehicle control, \# p<0.05 compared to the Cd model, \#\# p<0.01 compared to the Cd model.

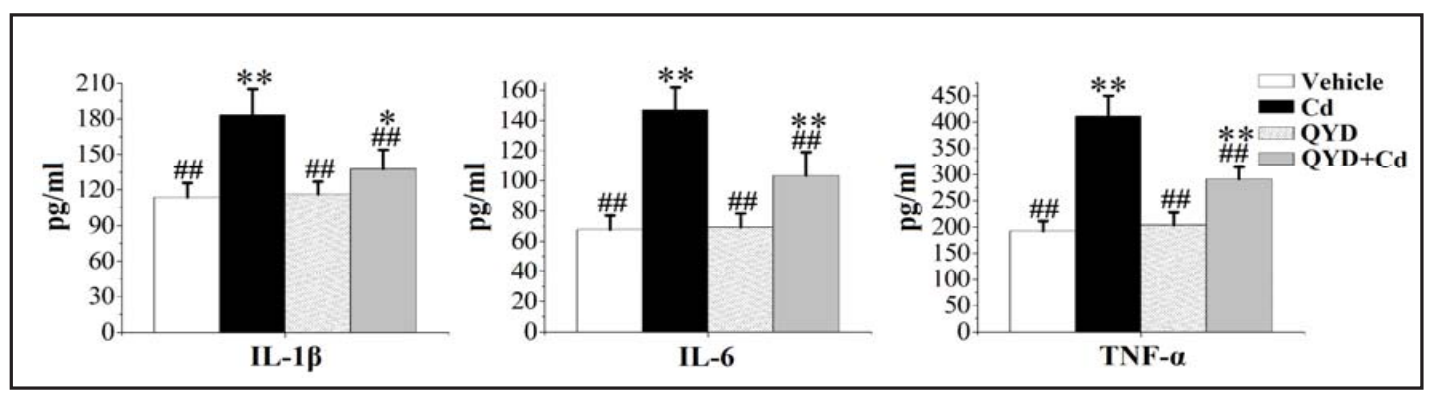

Fig. 3. Evaluation for the prostatic inflammation. Effects of QYD on the prostatic levels of IL-1 $\beta$, IL- 6 and TNF- $\alpha$ in rats injected with $\mathrm{Cd}$. ${ }^{*} \mathrm{p}<0.05$ compared to the vehicle control, ${ }^{* *} \mathrm{p}<0.01$ compared to the vehicle control, \#\# p<0.01 compared to the Cd model.

Fig. 4. Analysis for prostatic EMT markers. Effects of QYD on prostatic levels of E-cadherin, fibronectin, vimentin and $\alpha$-SMA in rats injected with Cd. * p<0.05 compared to the vehicle control, ** $\mathrm{p}<0.01$ compared to the vehicle control, \# p<0.05 compared to the Cd model, \#\# $\mathrm{p}<0.01$ compared to the $\mathrm{Cd}$ model.
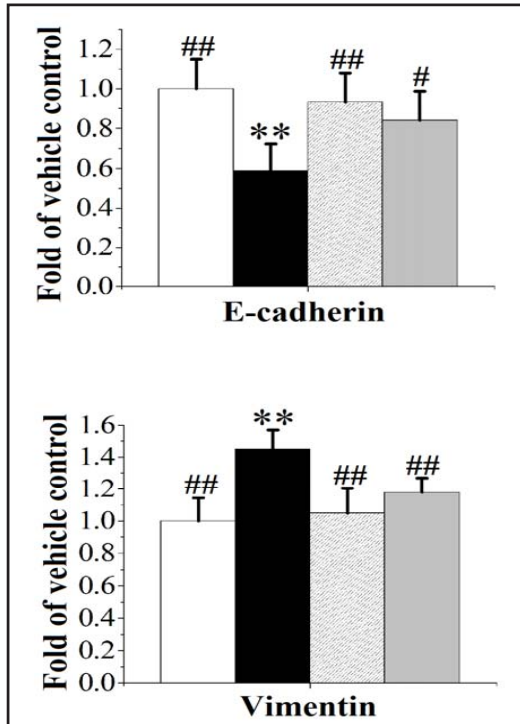

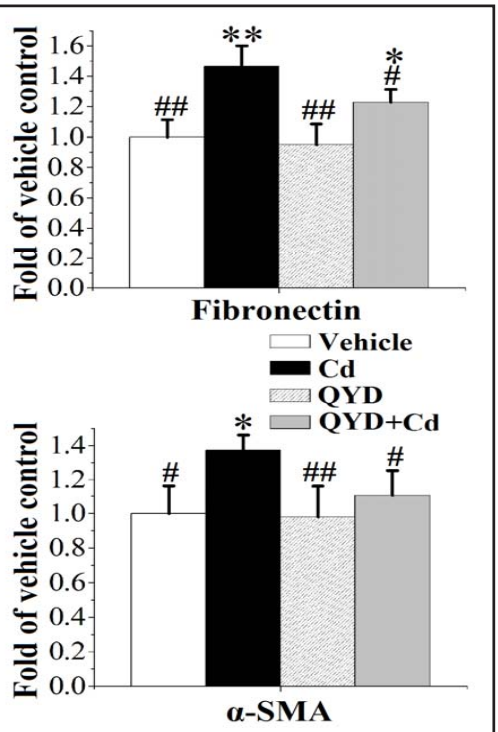

in the prostatic activities of SOD, CAT and GPx when compared to the Cd model group. Fig. 3 shows that the prostatic levels of IL-1 $\beta$, IL- 6 and TNF- $\alpha$ were significantly increased in rats injected with Cd when compared to the vehicle control. QYD obviously alleviated these Cd- 


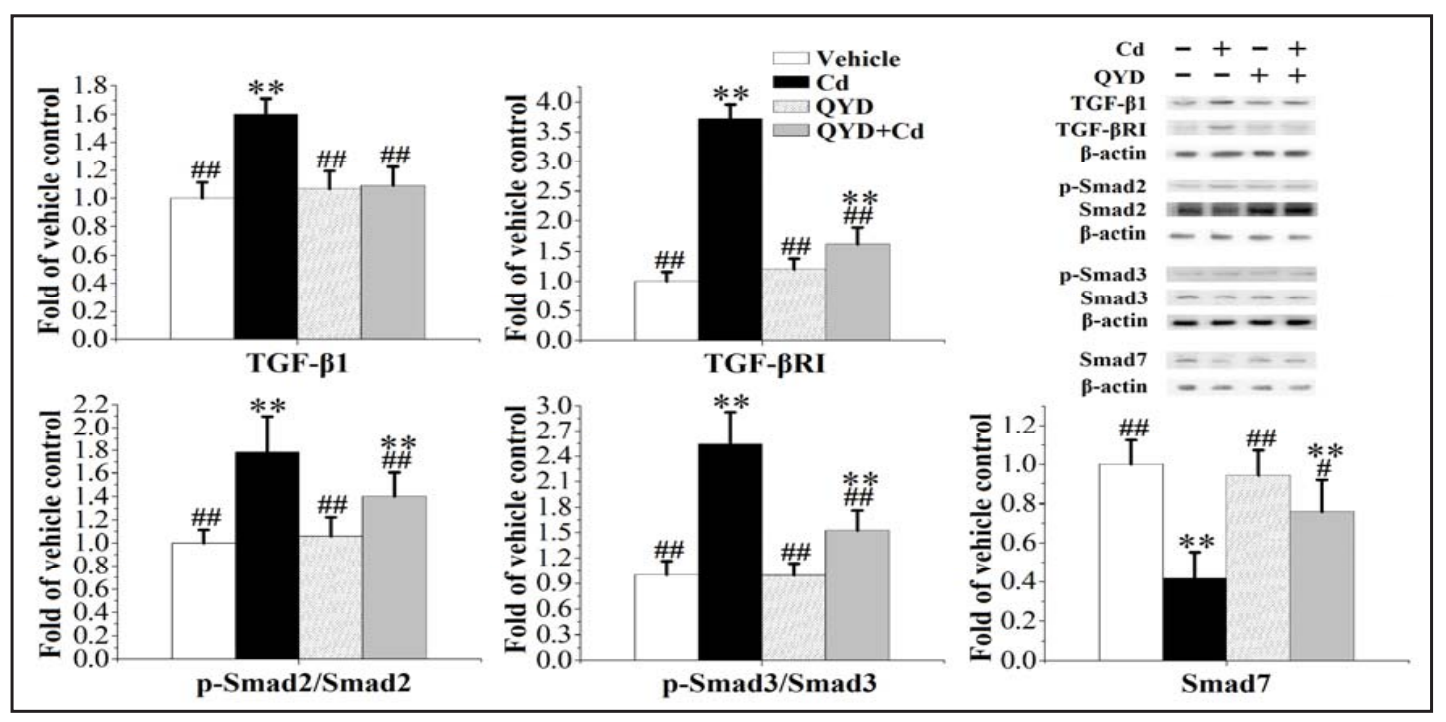

Fig. 5. Effects of QYD on prostatic expressions of TGF- $\beta 1$, TGF- $\beta$ RI, Smad2, p-Smad2, Smad3, p-Smad3 and Smad7 in rats injected with $\mathrm{Cd}$. ${ }^{* *} \mathrm{p}<0.01$ compared to the vehicle control, \# $\mathrm{p}<0.05$ compared to the Cd model, \#\# p<0.01 compared to the Cd model.

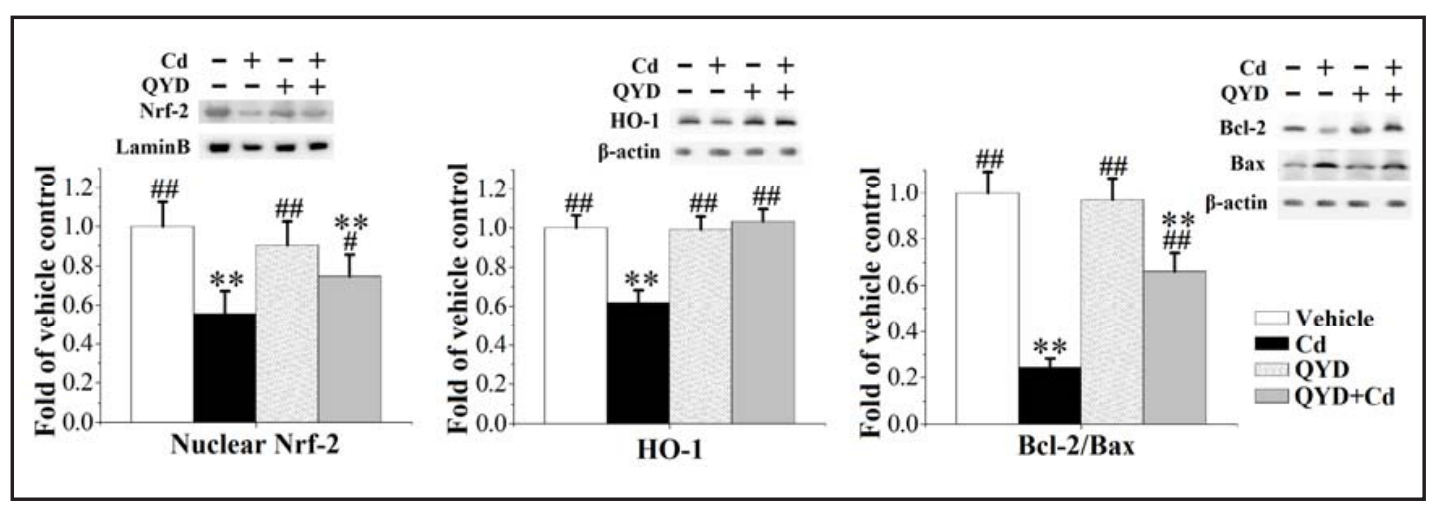

Fig. 6. Effects of QYD on prostatic expressions of Nrf-2, HO-1, Bcl-2 and Bax in rats injected with Cd. ** $\mathrm{p}<0.01$ compared to the vehicle control, \# $\mathrm{p}<0.05$ compared to the Cd model, \#\# $\mathrm{p}<0.01$ compared to the Cd model.

induced enhancements in the levels of pro-inflammatory cytokines when compared to the Cd model group.

\section{Effects of QYD on prostatic EMT}

The prostatic levels of E-cadherin, vimentin, $\alpha$-SMA and fibronectin are described in Fig. 4. Cd resulted in much lower mRNA level of E-cadherin and higher levels of vimentin, $\alpha$-SMA and fibronectin when compared to the vehicle control. These Cd-induced alterations in prostatic mRNA levels of E-cadherin, vimentin, $\alpha$-SMA and fibronectin were significantly restored by $200 \mathrm{mg} / \mathrm{kg} / \mathrm{d}$ QYD when compared to the Cd model group.

Effects of QYD on prostatic expressions of TGF- $\beta 1$, TGF- $\beta R I$, Smad2, p-Smad2, Smad3, $p$-Smad 3 and Smad7

The effects of QYD on modulating the prostatic expressions of TGF- $\beta 1$, TGF- $\beta$ RI, Smad2, p-Smad2, Smad3, p-Smad3 and Smad7 in rats injected with Cd are indicated in Fig. 5. Cd 
induced significant enhancements in prostatic expressions of TGF- $\beta 1$ and TGF- $\beta$ RI, as well as in phosphorylated levels of Smad2 and Smad3. The expression of Smad7 was noticeably reduced when compared to the vehicle control. Daily treated with $200 \mathrm{mg} / \mathrm{kg}$ QYD obviously decreased the expressions of TGF- $\beta 1$ and TGF- $\beta$ RI, inhibited the phosphorylations of Smad2 and Smad3, and increased the expression of Smad7 when compared to the Cd model group.

\section{Effects of QYD on prostatic expressions of Bcl-2, Bax, Nrf-2 and HO-1}

Fig. 6 reveals the effects of QYD on regulating the prostatic expressions of Bcl-2, Bax, HO-1 and nuclear Nrf-2. Cd decreased the expression of Bcl-2 and increased the expression of Bax. As a result, the ratio of Bcl-2/Bax was significantly reduced when compared to the vehicle control. QYD significantly enhanced the prostatic expression of Bcl-2 and reduced the expression of Bax when compared to the $\mathrm{Cd}$ model control. Meanwhile, the expressions of HO-1 and nuclear Nrf-2 were inhibited by Cd injection when compared to the vehicle control. Treatment with $200 \mathrm{mg} / \mathrm{kg} / \mathrm{d}$ QYD contributed to increased expressions of HO-1 and nuclear Nrf-2 when compared to the Cd model control.

\section{Discussion}

The impacts of environmental pollution on the reproductive system have attracted more and more attentions. Several studies report that $\mathrm{Cd}$ exposure produces harmful effects on prostate, testicle and sperm $[6,8,13]$. The orally $\mathrm{LD}_{50}$ of $\mathrm{CdCl}_{2}$ is suggested to be $90 \mathrm{mg} / \mathrm{kg}$ [14]. However, the effects of relative low dose Cd exposure on the proliferation and apoptosis of prostate cells are not consistent. A single dose of Cd exposure induces hyperplasia via exerting potent androgen and estrogen like activities on prostate [15]. Daily exposed to Cd for a long time stimulates prostatic inflammation and stromal fibrillar rearrangement, but does not promote the proliferation of prostatic cells [7]. Abdelrazek et al. found that Cd reduced the prostate weight via promoting cells apoptosis [14]. A possible hypothesis is that short-time Cd exposure induces the apoptosis of prostate cells, while chronic exposure to $\mathrm{Cd}$ may stimulate cells growth. The molecular mechanism was related to the ratio of Bcl-2/ Bax [16]. In the present study, we found that QYD attenuated Cd-induced over-production of pro-inflammatory cytokines and decreased the Bcl-2/Bax ratio. The exact mechanisms under the heavy metal stimulated disorders have not been fully elucidated. It is proposed that $\mathrm{Cd}$-induced tissue toxicity is mainly caused by oxidative damage [17-19]. Under the normal physiological conditions, the damages induced by oxidative stress are prevented by the enzymatic (such as SOD, CAT and GPx) and non-enzymatic (including GSH and Zinc (Zn)) defense systems in vivo [13]. These antioxidant enzymes can not only remove the free radicals by biochemical reactions, but also enhance the synthesis and regeneration of GSH. GSH is the most abundant endogenous non-enzymatic antioxidant and has the function of cleaning $\mathrm{H}_{2} \mathrm{O}_{2}$ into the harmless $\mathrm{H}_{2} \mathrm{O}$ [20]. On the one hand, $\mathrm{Cd}$ deactivates the antioxidant enzymes through binding to their sulfhydryl groups in the bioactive sites. On the other hand, $\mathrm{Cd}$ alters the levels of $\mathrm{Zn}$ via replacing $\mathrm{Zn}$ in tissues [13]. In human prostate, the local level of $\mathrm{Zn}$ is about 3-7 fold higher than that in the other organs. It has been well documented that $\mathrm{Zn}$ promotes the apoptosis of human prostate cancer and benign hyperplasia cells, but does not affects the normal prostate cells [21]. When the balance of oxidation-antioxidation is destroyed, the oxidative stress promoted tissue deficits emerge. MDA and NO are suggested to be the markers of Cd-induced oxidative stress [22]. MDA indicates the degree of cell membranes damages induced by organic lipid peroxidation [23]. NO is an essential transcellular messenger. NO can oxidize the sulfhydryl groups via associating with $\mathrm{O}^{2-}$ [24].

When the body suffers from toxic stimuli, several defensive mechanisms will be triggered concurrently in the early stage. However, death and malignancy seem be the ends of a continuum of cellular responses to $\mathrm{Cd}$ when the stress exceeds the body's abilities of adaptation and survival [20]. Nrf-2 is a redox-modulated transcription factor and belongs to the Cap" $n$ " Collar family of basic leucine zipper proteins. As a self-preservation program, 


\section{Cellular Physiology Cell Physiol Biochem 2017;43:1359-1368 \\ \begin{tabular}{ll|l} 
DOI: 10.1159/000481847 & $\begin{array}{l}\text { O 2017 The Author(s). Published by S. Karger AG, Basel } \\
\text { www.karger.com/cpb }\end{array}$ \\
\hline
\end{tabular}}

Du et al.: Qing Ye Dan Protects Against Prostatic Deficits

Nrf-2 plays a crucial role in the antioxidant defense mechanism against oxidative stress [24]. Kelch-like ECH associating protein-1 (keap-1) is a cytoplasmic Nrf-2 binding protein and is embedded in the cytoskeleton. Under normal conditions, Nrf-2 localizes in the cytoplasm and interacts with keap- 1 to form the keap-1/Nrf-2 complex. This Nrf-2/keap-1 complex is dissociated when exposed to reactive oxygen species (ROS). Subsequently, Nrf-2 is dissociated, stabilized and translocated into the nucleus [20]. As a cell survival signaling, the activation of Nrf-2 will accelerate the production of endogenous antioxidant enzymes (including HO1 , CAT and SOD) via binding to the antioxidant response element in the promoter regions of these genes, and subsequently inducing their transcriptions [25]. Furthermore, HO-1 possessed both anti-inflammatory and anti-oxidative properties in response to oxidative stress [24]. And Nrf-2 can enhance the production of anti-apoptotic protein Bcl-2 [20].

ROS are involved in EMT [26]. EMT is the process of epithelial cells transform to mesenchymal cells and characterized by diminished production of E-cadherin and overgeneration of fibronectin, $\alpha$-SMA and vimentin $[12,27,28]$. EMT usually participates in wound healing and tissue regeneration. However, aberrant activation of EMT drives organ fibrosis and malignant transformation via causing epithelial cells to lose their polarity and contacts, producing mesenchymal cells and fibroblasts [26, 29]. Among the above EMT markers, E-cadherin belongs to epithelial genes and contributes to the cellular adhesion. Fibronectin can modulate the growth and migration of cells [27]. $\alpha$-SMA is a contractile protein. It is necessary for the phenotypically modulated fibroblasts and for the generation of extracellular matrix (ECM) proteins [30]. Vimentin contributes to maintain the architecture of the cytoplasm. Aberrant vimentin expression during EMT is suggested to be an essential element for epithelial plasticity and malignant phenotype transformation of prostate cancer [31].

EMT can be triggered by external stimuli via TGF- $\beta 1$ signaling pathway [29]. TGF- $\beta 1$ is a powerful pro-fibrogenic cytokine. It modulates the phenotype, proliferation and functions of fibroblasts, promotes the transdifferentiation of myofibroblasts, as well as induces the deposition of ECM $[23,25]$. TGF- $\beta$ superfamily elicit signaling through distinctly combining to their transmembrane receptors (TGF- $\beta$ RI and II) [30]. Briefly, TGF- $\beta 1$ binds to TGF- $\beta$ RI and then directly stimulates the activation of Smad2 and Smad3 through phosphorylation [24]. The Smad7 serves as a negative regulator by binding to TGF- $\beta$ RI and antagonizing TGF- $\beta 1$ signaling [30]. TGF- $\beta 1$ is (at least partly) modulated by inflammatory mediators and oxidative stress [11]. TGF- $\beta 1$ also can increase the production of ROS, decrease the generation of GSH and suppress the activities of antioxidant enzymes [32,33]. It is in agreement with the results of our study. Cd significantly enhanced the prostatic EMT, promoted the prostatic oxidative stress and inflammation, activated TGF- $\beta 1 /$ Smad pathway, reduced Bcl-2/Bax ratio and inhibited Nrf-2/HO-1 signaling pathway. QYD administration at the dose of 200 $\mathrm{mg} / \mathrm{kg} / \mathrm{d}$ significantly ameliorated these $\mathrm{Cd}$ induced prostatic deficits.

In conclusion, the whole results indicated that QYD had protective effects against $\mathrm{Cd}$ induced prostatic damages via modulating Nrf-2/HO-1 and TGF- $\beta 1 /$ Smad signaling pathways. The present study added new insights for understanding the Cd-induced prostatic deficits and the possible mechanisms under the protective nature of QYD. Further investigation about the effects of QYD on the prostate chronic exposed to $\mathrm{Cd}$ for a long time will continue to be researched in the future.

\section{Acknowledgements}

This research is supported by the Natural Science Fund of Health and Family Planning Commission of Wuhan Municipality, China [grant numbers WZ17Q05], by the State Natural Sciences Fund of China [grant numbers 81603177], by Hubei Province health and family planning scientific research project [grant numbers WJ2017M189] and by the Youth Science and Technology Plan of Wuhan, China [grant numbers 2015071704011629]. 


\section{Cellular Physiology Cell Physiol Biochem 2017;43:1359-1368

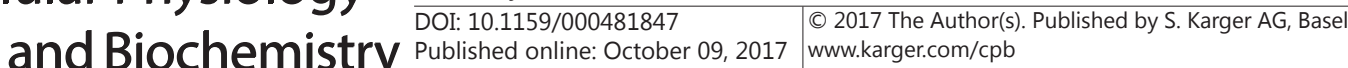 \\ Du et al.: Qing Ye Dan Protects Against Prostatic Deficits}

\section{Disclosure Statement}

The authors declare that there are no conflicts of interest.

\section{References}

1 Chakraborty K, Chatterjee S, Bhattacharyya A: Modulation of phenotypic and functional maturation of murine bone-marrow-derived dendritic cells (BMDCs) induced by cadmium chloride. Int Immunopharmacol 2014;20:131-140.

-2 Li CC, Wang Y, Li GY, Yun YL, Dai YJ, Chen J, Peng Y: Transcriptome profiling analysis of wolf spider Pardosa pseudoannulata (Araneae: Lycosidae) after cadmium exposure. Int J Mol Sci 2016;17: E2033.

-3 Imafidon CE, Akomolafe RO, Abubakar SA, Ogundipe OJ, Olukiran OS, Ayowole OA: Amelioration of cadmium-induced nephropathy using polyphenol-rich extract of Vernonia amygdalina (Del.) leaves in rat model. Open Access Maced J Med Sci 2015;3:567-577.

-4 Abarikwu SO, Adebayo OL, Otuechere CA, Iserhienrhien BO, Badejo TA: Selenium and rutin alone or in combination do not have stronger protective effects than their separate effects against cadmium-induced renal damage. Pharm Biol 2016;54:896-904.

5 Zhou Z, Lu YH, Pi HF, Gao P, Li M, Zhang L, Pei LP, Mei X, Liu L, Zhao Q, Qin QZ, Chen Y, Jiang YM, Zhang $\mathrm{ZH}, \mathrm{Yu} \mathrm{ZP}$ : Cadmium exposure is associated with the prevalence of dyslipidemia. Cell Physiol Biochem 2016;40:633-643.

6 Wang HF, Chang M, Peng TT, Yang Y, Li N, Luo T, Cheng YM, Zhou MZ, Zeng XH, Zheng LP: Exposure to cadmium impairs sperm functions by reducing CatSper in mice. Cell Physiol Biochem 2017;42:44-54.

7 Santana VP, Salles ÉS, Correa DE, Gonçalves BF, Campos SG, Justulin LA, Godinho AF, Scarano WR: Longterm effects of perinatal exposure to low doses of cadmium on the prostate of adult male rats. Int J Exp Pathol 2016;97:310-316.

8 Ngalame NN, Waalkes MP, Tokar EJ: Silencing KRAS Overexpression in cadmium-transformed prostate epithelial cells mitigates malignant phenotype. Chem Res Toxicol 2016;29:1458-1467.

-9 Arriazu R, Durán E, Pozuelo JM, Santamaria L: Expression of lysophosphatidic acid receptor 1 and relation with cell proliferation, apoptosis, and angiogenesis on preneoplastic changes induced by cadmium chloride in the rat ventral prostate. PLoS One 2013;8:e57742.

10 Lacorte LM, Rinaldi JC, Justulin LA Jr, Delella FK, Moroz A, Felisbino SL: Cadmium exposure inhibits MMP2 and MMP9 activities in the prostate and testis. Biochem Biophys Res Commun 2015;457:538-541.

11 Gharaee-Kermani M, Moore BB, Macoska JA: Resveratrol-mediated repression and reversion of prostatic myofibroblast phenoconversion. PLoS One 2016;11:e0158357.

12 Wu X, Gu Y, Li L: The anti-hyperplasia, anti-oxidative and anti-inflammatory properties of Qing Ye Dan and swertiamarin in testosterone-induced benign prostatic hyperplasia in rats. Toxicol Lett 2017;265:9-16.

13 Jahan S, Zahra A, Irum U, Iftikhar N, Ullah H: Protective effects of different antioxidants against cadmium induced oxidative damage in rat testis and prostate tissues. Syst Biol Reprod Med 2014;60:199-205.

14 Abdelrazek HM, Helmy SA, Elsayed DH, Ebaid HM, Mohamed RM: Ameliorating effects of green tea extract on cadmium induced reproductive injury in male Wistar rats with respect to androgen receptors and caspase-3. Reprod Biol 2016;16:300-308.

15 Prajapati A, Rao A, Patel J, Gupta S, Gupta S: A single low dose of cadmium exposure induces benign prostate hyperplasia like condition in rat: A novel benign prostate hyperplasia rodent model. Exp Biol Med 2014;239:829-841.

16 Luevano J, Damodaran C: A review of molecular events of cadmium-induced carcinogenesis. J Environ Pathol Toxicol Oncol 2014;33:183-194.

17 Raghuvanshi R, Chaudhari A, Kumar GN: Amelioration of cadmium- and mercury-induced liver and kidney damage in rats by genetically engineered probiotic Escherichia coli Nissle 1917 producing pyrroloquinoline quinone with oral supplementation of citric acid. Nutrition 2016;32:1285-1294.

18 Chen ZY, Liu C, Lu YH, Yang LL, Li M, He MD, Chen CH, Zhang L, Yu ZP, Zhou Z: Cadmium exposure enhances bisphenol A-induced genotoxicity through 8-oxoguanine-DNA glycosylase-1 OGG1 inhibition in NIH3T3 fibroblast cells. Cell Physiol Biochem 2016;39:961-974. 


\section{Cellular Physiology Cell Physiol Biochem 2017;43:1359-1368 \begin{tabular}{ll|l} 
DOI: 10.1159/000481847 & $\begin{array}{l}\text { O 2017 The Author(s). Published by S. Karger AG, Basel } \\
\text { www.karger.com/cpb }\end{array}$ \\
\hline
\end{tabular} \\ Du et al.: Qing Ye Dan Protects Against Prostatic Deficits}

19 Hu KH, Li WX, Sun MY, Zhang SB, Fan CX, Wu Q Zhu W, Xu X: Cadmium induced apoptosis in MG63 cells by increasing ROS, activation of p38 MAPK and inhibition of ERK $1 / 2$ pathways. Cell Physiol Biochem 2015;36:642-654.

20 Thévenod F, Lee WK: Cadmium and cellular signaling cascades: Interactions between cell death and survival pathways. Arch Toxicol 2013;87:1743-1786.

-21 Lin SF, Wei H, Maeder D, Franklin RB, Feng P: Profiling of zinc-altered gene expression in human prostate normal vs. cancer cells: A time course study. J Nutr Biochem 2009;20:1000-1012.

22 Chen J, Du L, Li J, Song H: Epigallocatechin-3-gallate attenuates cadmium-induced chronic renal injury and fibrosis. Food Chem Toxicol 2016;96:70-78.

-23 Liu ZH, Fan W, Chen RC: 3, 4-dihydroxyphenylethanol suppresses irradiation-induced pulmonary fibrosis in adult rats. Int J Clin Exp Pathol 2015;8:3441-3450.

-24 Adil M, Kandhare AD, Ghosh P, Bodhankar SL: Sodium arsenite-induced myocardial bruise in rats: Ameliorative effect of naringin via TGF- $\beta$ /Smad and Nrf/HO pathways. Chem Biol Interact 2016;253:66-77.

$>25$ You H, Wei L, Sun WL, Wang L, Yang ZL, Liu Y, Zheng K, Wang Y, Zhang WJ: The green tea extract epigallocatechin-3-gallate inhibits irradiation-induced pulmonary fibrosis in adult rats. Int J Mol Med 2014;34:92-102.

26 Jung SH, Kim SM, Lee CE: Mechanism of suppressors of cytokine signaling 1 inhibition of epithelialmesenchymal transition signaling through ROS regulation in colon cancer cells: Suppression of Src leading to thioredoxin up-regulation. Oncotarget 2016;7:62559-62571.

27 Gonzalez-Moreno 0, Lecanda J, Green JE, Segura V, Catena R, Serrano D, Calvo A: VEGF elicits epithelialmesenchymal transition (EMT) in prostate intraepithelial neoplasia (PIN)-like cells via an autocrine loop. Exp Cell Res 2010;316:554-567.

28 Park SA, Kim MJ, Park SY, Kim JS, Lee SJ, Woo HA, Kim DK, Nam JS, Sheen YY: EW-7197 inhibits hepatic, renal, and pulmonary fibrosis by blocking TGF- $\beta /$ Smad and ROS signaling. Cell Mol Life Sci 2015;72:20232039.

29 Sun L, Fang J: Epigenetic regulation of epithelial-mesenchymal transition. Cell Mol Life Sci 2016;73:44934515.

30 Biernacka A, Dobaczewski M, Frangogiannis NG: TGF- $\beta$ signaling in fibrosis. Growth Factors 2011;29:196202.

-31 Lean FZ, Kontos S, Palmieri C: Expression of $\beta$-catenin and mesenchymal markers in canine prostatic hyperplasia and carcinoma. J Comp Pathol 2014;150:373-381.

32 Kao HF, Chang-Chien PW, Chang WT, Yeh TM, Wang JY: Propolis inhibits TGF- $\beta 1$-induced epithelialmesenchymal transition in human alveolar epithelial cells via PPAR $\gamma$ activation. Int Immunopharmacol 2013;15:565-574.

-33 Liu RM, Desai LP: Reciprocal regulation of TGF- $\beta$ and reactive oxygen species: A perverse cycle for fibrosis. Redox Biol 2015;6:565-577. 